\title{
RESEARCH UPDATES
}

\section{The role of religiosity in families at high-risk for depression}

\section{Le rôle de la religiosité dans des familles à fort risque de dépression}

\author{
Connie Svob (Ph.D.) ${ }^{a, b}$, \\ Myrna M. Weissman (Ph.D.) ${ }^{a, b, c, *}$
}

\author{
a Department of Psychiatry, Vagelos College of Physicians and Surgeons, Columbia University, \\ New York, NY, USA \\ ${ }^{\mathrm{b}}$ Division of Translational Epidemiology, New York State Psychiatric Institute, New York, NY, \\ USA \\ c Mailman School of Public Health, Columbia University, New York, NY, USA
}

Received 15 January 2019; accepted 20 March 2019

\section{KEYWORDS \\ Clinical; Longitudinal; Neurobiology; Religion/spirituality; Risk for depression}

\begin{abstract}
Summary
Background. - About 40 years ago we began a study of the offspring of depressed (high-risk) and not depressed (low-risk) parents, matched for age and gender, from the same community. We interviewed all of their biological children, blind to the clinical status of the parents. Over the years, we returned to re-interview the families at baseline, 2, 10, 20, 25, 30, and 35 years. As the years went by and the sample grew up, we also interviewed the third generation, the grandchildren. As technology became available, we included measures of electrophysiology and magnetic resonance imaging in order to better understand the mechanisms of risk. At the 10-year follow up, we included measures of religion and spirituality - namely, personal religious/spiritual importance and frequency of religious service attendance. We included these measures in all subsequent waves including a more extensive follow up of religious beliefs at the 35-year follow up.

Issues of focus. - This paper describes the study design and highlights the key findings of the role of religious/spiritual belief in the transmission and endurance of depression using clinical and biological approaches.
\end{abstract}

* Corresponding author at: Columbia University Vagelos College of Physicians and Surgeons and New York State Psychiatric Institute, 1051, Riverside Drive, Unit 24, 10032 New York, NY, USA.

E-mail address: Myrna.Weissman@nyspi.columbia.edu (M.M. Weissman). 
Methods. - We describe study findings based on clinical measures, as well as physiological measures that employed electrophysiology and magnetic resonance imaging.

Results. - Taken together, the findings suggest that religiosity/spirituality is protective against depression in high-risk individuals at both clinical and physiological levels.

Implications. - The findings suggest religiosity interacts with both culture and biology in its impact on depression.

(c) 2019 Elsevier Masson SAS. All rights reserved.

\section{MOTS CLÉS}

Clinique ; Longitudinal ; Neurobiologie ; Religion/spiritualité ; Risque de dépression
This paper will summarize over 35 years of studying three generations of families at high and low risk for depression. High-risk is defined as having a parent/grandparent (i.e., generation 1) with moderate to serious major depression. Low-risk is defined as having no depression or other serious psychiatric illness in the first generation. Numerous findings have emerged from this study (see complete list of publications on our websites: https://www.brain-religion-project.org/; https://www.brain-religion-project.org/). The current paper will focus on the role of religiosity as a risk or protective factor. First, we will describe the context of the study - what led to it being conducted - and will give a brief overview of the major clinical findings. Then, we will describe how religion/spirituality became an interest and will outline the major outcomes. To end, we will outline where we are going with this research and its future directions.

\section{The initiation of the high-risk study}

When this study began in the early 1980s, the general belief that depression did not occur in childhood was being challenged by large-scale epidemiologic studies. These studies showed that the age of onset reported was often in adolescence or young adulthood, and sometimes even before puberty.

With an interest in prevention, early intervention, and determining risk factors that could help detection, the highrisk study began. Because it was well known that depression "ran in families," the motivation was that the biological offspring of depressed parents would be at high risk and if followed longitudinally, one could determine early signs of who was at risk and what factors increased risk or were protective. It was in this background that the highrisk study was initiated [1,2]. The study collected clinical assessments of the offspring at baseline and year 2. At 
year 10, we began assessing the grandchildren and continued assessments at years 20, 25, 30, 35, and 40. Year 40 is currently ongoing. The major findings of our study at 30 years $[3,4]$ were that offspring of depressed parents (generation 2) had increased rates of major depression (2-6 fold), beginning in adolescence or early adulthood. Anxiety disorders (before puberty), substance abuse in adulthood, more recurrence of major depressive disorder (MDD), more social impairment, more divorce, more treatment seeking, and increased mortality from unnatural causes [3,4]. Moreover, the grandchildren (generation 3) with two previous generations affected had a threefold increased risk of MDD, as well as an increased risk of suicidal behavior $[3,4]$.

We also investigated other risk factors in addition to family history of MDD that could help identify vulnerable persons. We found at baseline that poor marital adjustment, divorce, and family discord were more prevalent among high-risk parents. Therefore, parental depression in generation 1, which was a compilation of their various risk factors, was the most important predictor of MDD and other outcomes in the high-risk offspring. In the low-risk group where, by design, there was no depression in generation 1, the rates of depression were comparably low in the offspring and depression onset in offspring occurred with only one of these risk factors [5]. These results were replicated at 10year follow-up [6] and at 20-year follow-up [7] and were maintained as the offspring aged. The results demonstrated the problem in trying to disentangle an adverse environment from the effect of parental depression.

\section{Depression and religion}

With an interest in potential social risk factors that impact the transmission of depression in families, at the 10-year follow-up, and at all subsequent waves of data collection, we included a few questions about religiosity and spirituality. Specifically, we asked three general self-report questions that are commonly asked in the medical sciences [8]:

- belief in the personal importance of religion/spirituality: How important to you is religion or spirituality? on a 4point Likert scale (i.e., highly, moderately, slightly, or not at all important);

- religious service attendance: How often, if at all, do you attend church, synagogue, or other religious or spiritual services? on a 5-point Likert scale (once a week or more, about once a month, about once or twice a year, less than once a year, or never);

- denomination: Is there a particular denomination or religious organization that you are a part of?

\section{Depression}

In our first publication of these data, we showed that a mother's religious beliefs (personal sense of the importance of spirituality, not frequency of attendance at religious services) were highly protective against depression in her children over the prior 10-year period [9]. These effects were independent of maternal/child bonding or mother's functional status, education, age, or social class. We further noted that women with a history of depression who said that religion was personally highly important to them, when compared with those who did not, were $80 \%$ protected against a recurrence over the prior 10 years.

We replicated our findings on the protective effect of $\mathrm{R} / \mathrm{S}$ with data collected ten years later at year 20 [10]. Offspring who reported at year 10 that religion or spirituality was highly important to them had about one-fourth the risk of experiencing major depression between years 10 and 20. Only religious/spiritual beliefs, not religious attendance and denomination, significantly predicted this outcome. The effect was most pronounced among offspring at high familial risk for depression, and the protective effect was found primarily against recurrence of depression.

We followed up these findings once again at year 30 [11]. With the offspring reaching midlife (mean age $=47.5$ years, $\mathrm{SD}=6.9$ ), it allowed us to examine the association between $\mathrm{R} / \mathrm{S}$ and major depression at a later life stage. Interestingly, ratings of high R/S importance at year 20 were associated with an increased risk for depression at year 30 . This somewhat surprising finding suggests that the relation between $\mathrm{R} / \mathrm{S}$ and depression may vary across the lifespan. Whereas $\mathrm{R} / \mathrm{S}$ importance may be protective against depression in early adulthood, it may not have the power to buffer against challenges incurred at midlife. The emergence of adverse medical conditions may also be related to this effect as subjects continue to age. Future research will use the expanded $\mathrm{R} / \mathrm{S}$ survey measures, as well as medical data, to test more specifically what may be driving the protective effects of $\mathrm{R} / \mathrm{S}$ importance in early adulthood, but not in midlife.

If $\mathrm{R} / \mathrm{S}$ beliefs and practices indeed provided protection against psychiatric disorders, as we had found, we wondered whether depression impacted the transmission of religious beliefs and practices across generations, thereby increasing or mitigating risk for depression. We examined this question between generation 2 and generation 3 across ten years. Overall, we found relatively high rates of concordance between the two generations on measures of $R / S$ importance, attendance, and denomination [12]. Maternal depression, however, decreased the transmission of R/S importance reported by children, but did not decrease the frequency of attendance or change reported denomination. In fact, the children who reported concordance with their mother's denomination had a 91\% decreased chance of depression or anxiety in both the high- and low-risk groups.

\section{Adversity and resilience}

We were also interested in the capacity of religious beliefs and practices to protect against the effects of negative life events (Table 1), or to produce resilience (i.e., lower odds for developing clinical disorders) over time specifically, in our study, between year 10 and year 30 . We found that increased religious attendance was associated with significantly reduced odds for mood disorder (by 43\%) and any psychiatric disorder (by 53\%) in all offspring [13]. The reduction was significantly lower in offspring of non-depressed than depressed parents. For high-risk participants, increased attendance was associated with reduced MDD, mood disorder and any disorder, and increased importance of R/S was associated with reduced odds for mood disorder only for individuals with negative life events. Using 
Table 1 Percentage of participants with capacity to withstand adversity (negative life events) 10 to 20 years.

\begin{tabular}{ll}
\hline Negative Life Event & $\%$ \\
\hline Death of family member or close partner & 65 \\
Separation or divorce from partner or spouse & 40 \\
Serious illness in family member & 37 \\
Lost job & 27 \\
Drug or mental health problem in family member & 19 \\
Victim of crime or assault & 19 \\
Lost a close friend & 17 \\
Serious illness (self) & 13 \\
Family member in legal trouble & 11 \\
Witness to a crime or assault & 10 \\
Suicide attempt by family member & 9 \\
Problems on the job & 8 \\
Legal trouble (self) & 6 \\
Other & 16 \\
\hline
\end{tabular}

Global Assessment Scale (GAS) scores as measures of longitudinal change in psychosocial function, we likewise found greater improvement with religious involvement in more vulnerable offspring [14]. Together, the findings underscore the importance of religious beliefs and practices in protecting against mood disorders over time.

\section{Suicidal behavior}

We also extended our findings on the protective effects of a parent's belief in R/S importance on offspring depression and mood disorders to offspring suicidal behavior $[15,16]$. Specifically, we investigated the effect of parent (generation 2) religiosity on suicidal behavior of their children aged 6-18 years (generation 3) over 20 years (years 10 to 30 ). A parent's belief in the high importance of religion was associated with an approximately $80 \%$ decrease in risk of suicidal ideation/attempts in their children compared to parents who reported religion as unimportant. The effect of parental belief was independent of the child's own belief in the importance of religion and other parental risk factors (e.g., parental history of suicidal behavior, depression, and divorce), and was statistically significant. We also found a protective effect of R/S importance and attendance against suicidal behavior in children and adolescents at high risk for depression, particularly in girls. This effect held for both prepubescent children and adolescents, respectively.

The clinical findings were so compelling that at year 20, as technology advanced, we began to consider the biological correlates of religiosity in greater depth, as well. Below we outline broadly some of our major findings.

\section{Biological correlates of religiosity and spirituality}

The biological processes that may predict R/S remain understudied (for a review, see [17]). Indeed, most of the brain studies on reflective processes have been restricted to mindfulness/meditation, which have pointed with remarkable consistency to a collection of brain regions, including regions related to attention (e.g., anterior prefrontal cortex), emotional regulation (orbitofrontal and anterior cingulate cortices), memory consolidation (hippocampus), bodily awareness (insula), and introspection (posterior cingulate cortex and other regions within the default mode network) [18]. The neurobiological correlates of religious belief, however, have scarcely been examined. Moreover, they have generally been limited by modest sample sizes, typically comparing groups of 10-20 participants, with limited statistical power for inferential confidence, and have been cross-sectional in design, precluding the capacity to probe fundamental questions related to adaptation, resilience, and causation.

\section{Neuroimaging findings}

\section{Magnetic resonance imaging (MRI)}

Our first imaging study from this cohort [19] reported anatomical MRI scans from biological descendants (children and grandchildren) of the original sample. We detected large expanses of prominent thinning (average $28 \%$ reduction in thickness) across the lateral aspects of the parietal, posterior temporal, and frontal cortices of the right hemisphere in the high-risk group. Thinning was observed even in persons from the high-risk group who never suffered from MDD or anxiety disorder, and it was present in analyses of both children (age $<18$ years) and adults, respectively, suggesting that cortical thinning could be a biological marker. Since the high-risk families had thinner cortices, but R/S importance was protective against depression, we reasoned that a person who reported R/S as highly important should have a thicker cortex.

We examined the association between R/S and cortical thinning [8]. Consistent with the earlier clinical findings, personal importance of $\mathrm{R} / \mathrm{S}$, but not frequency of attendance, was associated with thicker cortices in the left and right parietal and occipital regions and the mesial right frontal hemisphere. These findings suggested that thicker cortex is associated with high importance of religion, and that this association may confer resilience to the depression in individuals at high familial risk, possibly by expanding a cortical reserve that may counter the vulnerability that cortical thinning poses.

We followed up on these findings 5-8 years later to test their stability and to see if they would replicate. We found, in the same sample, that high R/S importance was associated with a larger pial surface and thicker cortex in the left superior frontal gyrus among individuals at high risk for depression [20], supporting the notion of cortical thickness as a protective biomarker related to R/S importance.

\section{Functional magnetic resonance imaging (fMRI)}

In a fMRI study using a directed attention task designed to identify error- and interference-related brain activations [21], we were also able to distinguish between endophenotypes for MDD risk and resilience: The risk endophenotype included greater activation of cortical attention circuits, while the resilience endophenotype included greater 
activation of the dorsal anterior cingulate cortex. We found that individuals with high $\mathrm{R} / \mathrm{S}$ importance showed reduced activation, and low R/S importance stronger activation, in regions that constitute the risk endophenotype.

We also examined the role of religiosity in default mode network (DMN) connectivity employing resting-state functional connectivity MRI (rs-fcMRI). Earlier, we had observed that individuals at risk for depression tended to have increased default mode network (DMN) connectivity [22]. In the same sample, however, we found that individuals who reported high R/S importance showed decreased default mode network connectivity - suggesting another potential protective biomarker of R/S importance [23].

\section{Electroencephalography (EEG)}

Posterior EEG alpha has been linked to relaxed mental states (e.g., in meditation, eyes closed while resting), as well as to clinical treatment response in depression [24]. As such, greater posterior alpha may be an indicator of resilience against depression. In our first EEG study, we found ratings of high R/S importance to be associated with posterior EEG alpha, especially in people at risk for depression [25]. This suggested that posterior EEG alpha may also be a protective biomarker associated with belief in R/S importance.

To follow up on this finding, we asked whether the same effects would be observed 20 years later-particularly, if people changed their personal ratings of $\mathrm{R} / \mathrm{S}$ importance [26]. We found that people who originally reported high ratings of R/S importance retained the high posterior alpha effects across time, even if they lowered their ratings of $\mathrm{R} / \mathrm{S}$ importance 20 years later. In contrast, this was not the case for individuals who only later rated R/S to be highly important. Interestingly, this suggests a possible "critical period" for acquiring optimal protective effects of R/S in early adulthood that may also help explain the clinical findings reported above at midlife [11]. This is also consistent with our finding that posterior alpha is highly stable over 12 years (i.e., indicative of an individual trait) if individuals have matured beyond adolescence [27].

\section{Diffusion tensor imaging (DTI)}

Finally, using DTI, we found that the microstructural differences associated with familial risk for depression in the precuneus, frontal lobe, and temporal lobe were weaker (i.e., non- or less-significant) in the group that reported high R/S importance. This corroborated our previous neurobiological findings and suggested that R/S also affects microstructures in the brain, which in turn may confer resilience against depression in individuals at high familial risk for the disorder [28].

\section{Current and future directions}

Up to this point, all of our findings have been based on three single self-report items. In an effort to deepen our understanding of religiosity/spirituality, we collected data on an extensive religion/spirituality survey. Therefore, in addition to our usual measures of R/S importance, denomination, and attendance, we obtained from $n=282$ individuals at high and low risk for depression extensive survey data on an array of religious constructs taken from previously validated, published scales. This survey sought to include a reasonably comprehensive set of both religious (i.e., facets of organized religion) and spiritual constructs (i.e., encompassing the broader spiritual dimension of the human person not dependent on affiliation with formal institutional religion) based on several R/S constructs suggested by Hill and Pargament [29].

We investigated the extended full R/S survey data through an a priori theoretical approach based on a large multi-national sample (from China, India, and the USA) that, through exploratory factor analysis, resulted in five invariant spirituality factors [30]. First, we replicated the five independent domains in our present high-risk sample [31], including Religious and Spiritual Commitment (the extent to which one gives priority in one's life to a Higher Power); Contemplative Practice (the frequency with which one engages in meditative spiritual practices); Sense of Interconnectedness (the degree to which one senses an underlying connection to other life forms); Experience of Love (the extent to which one experiences kindness and harmony with others); and Altruistic Engagement (degree to which one serves and cares for others). Exploratory analyses revealed correlations between these R/S factors and clinical and behavioral outcomes. Findings included inverse associations between R/S Commitment and a previous diagnosis of depression for individuals at high familial risk for depression. Interestingly, the other factors were not associated with a previous diagnosis of depression. These findings lead to several interesting questions, including: (1) Is there a causal pathway between R/S and depression? and (2) Do certain domains of R/S confer resilience, while others confer risk, in mental health outcomes? We are currently collecting data that will allow us to test prospectively whether the $\mathrm{R} / \mathrm{S}$ factors will predict a similar pattern of clinical diagnoses and biological correlates 3-5 years later.

Although preliminary in this scientific field, the overall consistency of our findings over time suggests a person's religious beliefs and practices should not be ignored by medical practitioners, including physicians, psychiatrists, and hospital chaplains. Taken together, for persons for whom religion and spirituality are important, these beliefs and practices may positively affect their own life, their children's lives, and be rooted in their biology.

\section{Funding}

This study was supported in part by John Templeton Foundation grants \#54679 and \#61330 (MMW) and NIMH grant 2-R01-MH36197 (MMW).

\section{Disclosure of interest}

In the past three years, Dr. Weissman received funding from the National Institute of Mental Health (NIMH), the Sackler Foundation, the Templeton Foundation, and receives royalties from the Oxford University Press, Perseus Press, the American Psychiatric Association Press, and MultiHealth Systems. Dr. Svob has no disclosures to report. 


\section{References}

[1] Weissman MM, Warner V, Wickramaratne P, et al. Offspring of depressed parents: 10 years later. Arch Gen Psychiatry 1997; 54:932-40.

[2] Weissman MM, Wickramaratne $P$, Nomura $Y$, et al. Offspring of depressed parents: 20 years later. Am J Psychiatry 2006;163:1001-8.

[3] Weissman MM, Berry 00, Warner V, et al. A 30-year study of 3 generations at high and low risk for depression. JAMA Psychiatry 2016;73:970-7.

[4] Weissman MM, Wickramaratne P, Gameroff MJ, et al. Offspring of depressed parents: 30 years later. Am J Psychiatry 2016;173:1024-32.

[5] Fendrich M, Weissman MM, Warner V. Longitudinal assessment of major depression and anxiety disorders in children. J Am Acad Child Adolesc Psychiatry 1990;30:67-74.

[6] Nomura Y, Wickramaratne P, Warner V, Mufson L, Weissman MM. Family discord, parental depression and psychopathology in offspring: 10-year follow-up. J Am Acad Child Adolesc Psychiatry 2002;41:402-9.

[7] Pilowsky D, Wickramaratne P, Nomura Y, Weissman M. Family discord, parental depression, and psychopathology in offspring: twenty-year follow-up. J Am Acad Child Adolesc Psychiatry 2006;45:452-60.

[8] Miller L, Bansal R, Wickramaratne P, et al. Neuroanatomical correlates of religiosity and spirituality: a study in adults at high and low familial risk for depression. JAMA Psychiatry 2014;71:128-35.

[9] Miller L, Warner V, Wickramaratne P, Weissman MM. Religiosity and depression: ten-year follow-up of depressed mothers and offspring. J Am Acad Child Adolesc Psychiatry 1997;36:1416-25.

[10] Miller L, Wickramaratne P, Gameroff MJ, Sage M, Tenke CE, Weissman MM. Religiosity and major depression in adults at high risk: a ten-year prospective study. Am J Psychiatry 2012;169:89-94.

[11] Anderson M, Miller L, Wickramaratne P, Svob C. Religiosity and depression at midlife: a prospective study. Clin Psychiatry [In Press].

[12] Jacobs M, Miller L, Wickramaratne P, Gameroff M, Weissman MM. Family religion and psychopathology in children of depressed mothers: ten-year follow-up. J Affect Disord 2012;136:320-7.

[13] Kasen S, Wickramaratne P, Gameroff MJ, Weissman MM. Religiosity and resilience in persons at high risk for major depression. Psychol Med 2012;42:509-19.

[14] Kasen S, Wickramaratne P, Gameroff MJ. Religiosity and longitudinal change in psychosocial functioning in adult offspring of depressed parents at high risk for major depression. Depress Anxiety 2014;31:63-71.

[15] Svob C, Reich L, Wickramaratne P, Zhao R, Warner V, Weissman MM. Religion and spirituality predict lower rates of suicide attempts and ideation in children and adolescents at risk for major depressive disorder. J Am Acad Child Adolesc Psychiatry 2016;55:S251.
[16] Svob C, Wickramaratne PJ, Reich L, et al. Association of parent and offspring religiosity with offspring suicide ideation and attempts. JAMA Psychiatry 2018;75:1062-70.

[17] Rim JI, Ojeda JC, Svob C, et al. Current understanding of religion, spirituality, and their neurobiological correlates [Under Review].

[18] Fox KC, Nijeboer S, Dixon ML, et al. Is meditation associated with altered brain structure? A systematic review and meta-analysis of morphometric neuroimaging in meditation practitioners. Neurosci Biobehav Rev 2014;43:48-73.

[19] Peterson BS, Warner V, Bansal R, et al. Cortical thinning in persons at increased familial risk for major depression. Proc Natl Acad Sci USA 2009;106:6273-8.

[20] Liu J, Svob C, Wickramaratne P, et al. Neuroanatomical correlates of familial risk-for-depression and religiosity/spirituality. Spiritual Clin Pract 2017;4:32-42.

[21] Peterson BS, Wang Z, Horga G, et al. Discriminating risk and resilience endophenotypes from lifetime illness effects in familial major depressive disorder. JAMA Psychiatry 2014;71:136-48.

[22] Posner J, Cha J, Wang Z, et al. Increased default mode network connectivity in individuals at high familial risk for depression. Neuropschopharmacology 2016;41:1759-67.

[23] Svob C, Wang Z, Weissman MM, Wickramaratne P, Posner J. Religious and spiritual importance moderate relation between default mode network connectivity and familial risk for depression. Neurosci Lett 2016;634:94-7.

[24] Tenke CE, Kayser J, Manna CBG, et al. Current source density measures of EEG alpha predict antidepressant treatment response. Biol Psychiatry 2011;70:388-94.

[25] Tenke CE, Kayser J, Miller L, et al. Neuronal generators of posterior EEG alpha reflect individual differences in prioritizing personal spirituality. Biol Psychol 2013;94:426-32.

[26] Tenke CE, Kayser J, Svob C, et al. Association of posterior EEG alpha with prioritization of religion or spirituality: a replication and extension at 20-year follow-up. Biol Psychol 2017;124:79-86.

[27] Tenke CE, Kayser J, Alvarenga JE, et al. Temporal stability of posterior EEG alpha over twelve years. Clin Neurophysiol 2018;129:1410-7.

[28] Li X, Weissman M, Talati A, et al. A diffusion tensor imaging study of brain microstructural changes related to religion and spirituality in families at high risk for depression. Brain Behav [In Press].

[29] Hill PC, Pargament KI. Advances in the conceptualization and measurement of religion and spirituality: implications for physical and mental health research. Am Psychol 2003;58: 64-74.

[30] McClintock CH, Lau E, Miller L. Phenotypic dimensions of spirituality: implications for mental health in China, India, and the United States. Front Psychol 2016;7:1600.

[31] McClintock CH, Anderson M, Svob C, et al. Multidimensional understanding of religiosity/spirituality: relationship to major depression and familial risk. Psychol Med 2018:1-10. 